\title{
A novel circulated air curtain system to confine the transmission of exhaled contaminants: A numerical and experimental investigation
}

\author{
Haixin Wang ${ }^{1}$, Hua Qian ${ }^{1}(\varangle)$, Rong Zhou ${ }^{2,3}(\varangle)$, Xiaohong Zheng ${ }^{1,4}$ \\ 1. School of Energy and Environment, Southeast University, Nanjing 210096, China \\ 2. First Affiliated Hospital of Guangzhou Medical University, Guangzhou 510000, China \\ 3. Guangzhou Angel Biosafety Co., Ltd, Guangzhou 510000, China \\ 4. Jiangsu Provincial Key Laboratory of Solar Energy Science and Technology, School of Energy and Environment, Southeast University, \\ Nanjing 210096, China
}

\begin{abstract}
Air curtain is an efficient device for cutting off airflow and confining contaminants. Inspired by the ability, a circulated air curtain composed of end-to-end plane jets generated by a relay of air pillars is proposed to confine exhaled contaminants in this study. Furthermore, the optimization study of computational fluid dynamics (CFD) is conducted to explore cutting-off performance and find better design parameters under different conditions, i.e., human-curtain distance, enclosure shape, jet velocity from air pillar, and exhalation modes. The multidirectional blockage and vortex-like rotative transmission routes of exhaled airflow are observed when air curtain exists. Results indicate that contaminants are concentrated around the source. The average mole fraction of exhaled contaminants outside air curtain under different human-curtain distance decreases $4.3 \%-19.6 \%$ compared to mixing ventilation with same flux. Shortening the human-curtain distance can improve the performance of air curtain and may change the direction of exhaled airflow. Moreover, It has better performance when the enclosure shape is close to a circle. Higher jet velocity is better for improving the confinement performance, but the trend is not very obvious as velocity increases. For exhalation modes, it is more challenging to control exhaled contaminants for intense exhalation activity (such as coughing) in steady simulation, but results in transient simulation show better performance when coughing only once. These results can provide a reference for the subsequent design and improvement in applying air curtain in hospital wards or other places, especially during the period of flu outbreak.
\end{abstract}

\author{
Keywords \\ air curtain, \\ CFD, \\ exhaled contaminants, \\ cutting off, \\ multidirectional blockage

\section{Article History} \\ Received: 01 November 2019 \\ Revised: 23 April 2020 \\ Accepted: 25 May 2020
() Tsinghua University Press and Springer-Verlag GmbH Germany, \\ part of Springer Nature 2020
}

\section{Introduction}

The outbreak of respiratory infections especially the emerging respiratory diseases in recent years has iterated the significance of infection control. Hundreds of millions of people suffer and four million people die prematurely from respiratory diseases each year (Ferkol and Schraufnagel 2014). The emerging outbreak of 2019 novel coronavirus diseases (COVID-19) has rapidly spread to nearly all countries worldwide and it had infected more than two million people, and killed nearly 160,000 people by 21 April 2020 (WHO 2020). How to reduce the risk from an infected person to a susceptible person has become an important topic for effective intervention.

\footnotetext{
E-mail: qianh@seu.edu.cn (Hua Qian); zhourong@vip.163.com (Rong Zhou)
}

Respiratory infectious diseases are considered to be transmitted via three routes, i.e., contact transmission, droplet transmission and airborne transmission (Wei and Li 2015). Pathogen-laden droplets will be exhaled into air when infectors are breathing, talking, coughing, or sneezing. Small droplets evaporate and become droplet nuclei quickly and disperse widely due to the airflow pattern (Chao et al. 2009). Large droplets can directly invade the nasal cavity or throat of susceptible people, which leads to the infection of the corresponding disease (Liu et al. 2017a). Abundant studies have been carried out to study the characteristics of number (Fairchild and Stampfer 1987; Lindsley et al. 2012), size (Xie et al. 2009), velocity (Kwon et al. 2012) and the dispersion of exhaled air or droplets (Chen and Zhao 2010; 


List of symbols
$\begin{array}{llll}C_{\mathrm{D}} & \text { drag coefficient } & & \\ d_{\mathrm{p}} & \text { particle diameter } & \Gamma_{\phi} & \text { the diffusion term } \\ \vec{F} & \text { additional acceleration (force/unit particle mass) } & \vec{u}_{\mathrm{p}} & \text { particle velocity } \\ & \text { term } & \mu & \text { fluid molecular viscosity } \\ g & \text { gravity acceleration } & \rho & \text { fluid density } \\ R e & \text { relative Reynolds number } & \rho_{\mathrm{p}} & \text { particle density } \\ S_{\phi} & \text { the source terms } & \phi & \text { general scalar quantity }\end{array}$

Yan et al. 2019). Further studies show that cross-infection problem is noticeable in hospitals through the research on worldwide severe acute respiratory syndrome (SARS) (Li et al. 2004, 2005). The relative distance, the posture and relative orientation of infected and exposed individuals are also important factors in determining the cross-infection risk (Liu et al. 2017a; Liu et al. 2019a).

Abundant studies show that the characteristic of airborne spread of exhaled contaminants between occupants is mostly influenced by the indoor airflow patterns. For example, it is observed that mixing ventilation (MV) shows a better effect in reducing the risk of cross-infection than displacement ventilation (DV) (Gao et al. 2008). Personalized Ventilation (PV) has an excellent performance in reducing the risk of airborne infection in indoor spaces (Sekhar and Zheng 2018; Liu et al. 2019b). However, previous studies show that the existing isolation room ventilation is not able to remove all respiratory particles effectively (Qian and Li 2010). The current droplet precautions and dilution ventilation are not effective in preventing short-range airborne transmission (Liu et al. 2017a). Many studies focus on preventing the dispersion trajectory of the exhaled airflow and contaminants between the infected source and the susceptible person, such as wearing a surgical mask (Zhu et al. 2006; Cowling et al. 2010) and cutting off exhaled jet using airflow (Qian et al. 2018), which have presented a positive effect on reducing the risk of infection. Previous research shows the physical partitioning of patients is also beneficial to the infection control in hospital environments by numerical and experimental studies (King et al. 2013). In the numerical work of Ching et al. (2008), curtain is found to be a good method to prevent airborne diseases and it can reduce the maximum concentration of bioaerosol by approximately $65 \%$. However, the hospital curtain is not flexible enough and affects patient's feelings, especially in hospital wards. Besides, many patients are not aware of the significance of wearing masks and don't wear masks. Therefore, other methods need to be explored for controlling the transmission of exhaled contaminants.

Air curtain, as a way of changing the airflow pattern, can be used to isolate two adjacent spaces. It is widely used in different fields to confine the penetration of contaminant (Ciocănea and Dragomirescu 2013), to control heat and moisture (Rivera et al. 2011), to provide an aerodynamic seal and reduce energy usage in whole building (Goubran et al. 2017), to protect cold storage room and food cabinets (Cao et al. 2011b; Gil-Lopez et al. 2014), to control the propagation of smoke and fire (Luo et al. 2017). For the design of air curtain, the technical dimensioning is studied and equations for the breakthrough momentum flux are presented based on the moment-of-momentum principle (Sirén 2003). Furthermore, previous works of Navaz et al. (2005) present a comprehensive discussion on air curtain performance characterization and optimization. In the field of indoor air quality, air curtains also display good performance in cutting off airborne transmission routes. Cao et al. (2011a) use air curtains to separate offices into different subzones to protect workers from exposure to respiratory diseases. In subsequent research, a new type of air distribution method called protected occupied zone ventilation (POV) is presented, in which protection efficiency varies from $8 \%$ to $50 \%$ depending on the exhaust location, supply air velocity and the usage of partitions (Cao et al. 2014). Shih et al. (2011) establishes a satisfactory shield for the constraint of pollutant dispersal using the air curtain device in a cleanroom and optimize the sealing performance by varying the parameters of ejection velocity, ejection angle and installation height. Recent work of Zhao et al. (2018) reveals that air curtain sealing efficiency increases positively with ejection velocity, and this trend is significant as the enclosure height is relatively low. However, these air curtain devices install on the ceiling level and supply air flows downward. The obvious flaws are that the device is fixed and cannot be moved freely. Besides, how the exhaled airflow interacts with air curtain airflow pattern remains unknown. It is of significance to carry out a study to examine and optimize the performance of air curtain for cutting off the transmission route of exhaled contaminants by more flexible methods. 
In this study, a kind of circulated air curtain system composed of end-to-end plane jets generated by a relay of air pillars is proposed, which can form the multidirectional blockage to cut off the transmission route of contaminants. Apart from this, it also has the advantages of small occupied area and convenient installation. It can be widely used in hospital wards, especially during the period of flu outbreak. Further, this paper investigates how the air curtain system confines the transmission of patient's exhalation airflow. The impact of quadrilateral air curtains on indoor airflow patterns and exhaled contaminant distribution is calculated to assess the performance of the air curtain. Afterward, the concentrations of tracer gas are compared between different human-curtain and mixing ventilation with the same airflow flux to further confirm the effect of the curtain system. Based on these, the exposure of the susceptible to the contaminants emitted by the infector is explored by considering the effects of air curtains with different enclosure shapes, jet velocity from air pillar, and human exhalation mode using steady and transient simulation.

\section{Methodologies}

\subsection{Description of the model}

The layout of the simulated room is illustrated in Figure 1, which is a standard case. To avoid the influence of the surrounding walls on the airflow pattern, the room size is set as $9 \mathrm{~m}(x$, width $) \times 9 \mathrm{~m}(z$, long $) \times 4 \mathrm{~m}(y$, high $)$, which has enough space to investigate the performance of air curtain. A manikin model (approximately $1.75 \mathrm{~m}$ tall), which acts as an infector, is placed in the center of the room. Four air pillars surround the patient and form a circulated air curtain system, quadrilateral in shape viewed from above, with four segments of relayed plane jets. The arrows in the top view refer to the direction of airflow in the air curtain. The widths of the inlet and the outlet are $20 \mathrm{~mm}$ and $40 \mathrm{~mm}$, respectively; the height of each air pillar is $2 \mathrm{~m}$; the distance between human and air pillars is $1.5 \mathrm{~m}$ (in accordance with the threshold distance in reference (Liu et al. 2017a)).

\subsection{CFD simulations}

Computational fluid dynamics (CFD) has been adopted as a useful tool to research that the exhaled airflow pattern and contaminant dispersion in the room. A standard case, as shown in Figure 1, is modeled first to simulate the airflow pattern and dispersion of droplets. The jet velocity from the air pillar is $3.5 \mathrm{~m} / \mathrm{s}$. A set of unstructured tetrahedral mesh is generated to cover the irregular solution domain featuring the complex geometry of the human model. Various refinement levels of the mesh are tested for the grid-independent solution. The governing equations for fluid flow are solved using the SIMPLE algorithm and second-order upwind scheme by Fluent 17.0. The RNG $k-\varepsilon$ turbulence model, widely tested in the prediction of room air distribution (e.g., Nielsen 2015; Yan et al. 2017), is chosen to calculate turbulent flows in the simulation. Non-slip boundary conditions are applied to all walls.

The governing equations can be expressed in a general vector form as follows:

$$
\begin{aligned}
& \frac{\partial \rho}{\partial t}+\operatorname{div}(\boldsymbol{V})=0 \\
& \frac{\partial(\rho \phi)}{\partial t}+\operatorname{div}(\rho \boldsymbol{V} \phi)=\operatorname{div}\left(\Gamma_{\phi} \operatorname{grad} \phi\right)+S_{\phi}
\end{aligned}
$$

where $V$ is the velocity vector, $\phi$ is a general scalar quantity,

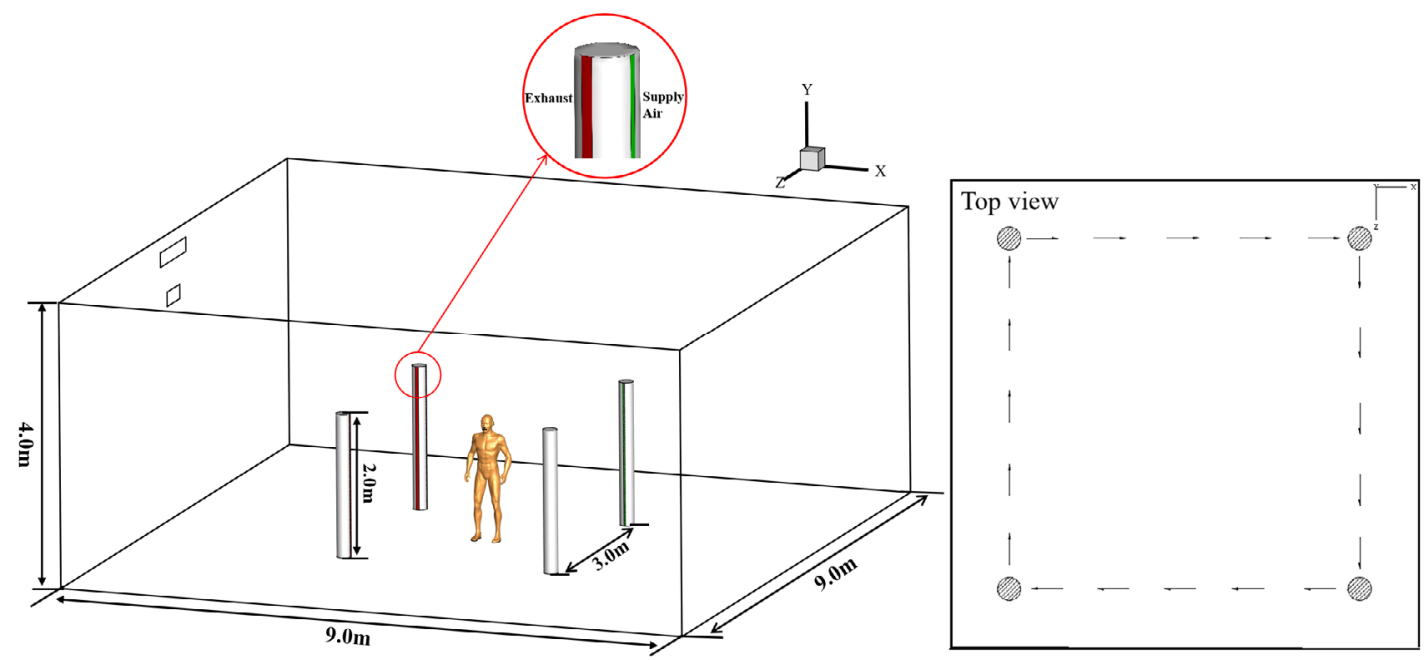

Fig. 1 The geometric model diagram of the quadrilateral air curtain 
which can represent three components of velocity, kinetic energy of turbulence $k$, dissipation rate of turbulence energy $\mathcal{\varepsilon}$, temperature $T$ and tracer gas concentration. $\rho$ is the fluid density, $\Gamma_{\phi}$ is the diffusion term, $S_{\phi}$ is the source term.

Species Transport Model is used and $\mathrm{N}_{2} \mathrm{O}$ is selected in the species as the tracer gas to indicate the contaminants in the exhaled airflow, with an initial volume fraction of $4 \%$, as in Liu et al. (2017a) and Ji et al. (2018). Discrete Phase Model (DPM) is also implemented to simulate the transmission process of exhaled droplets in the room. The particle trajectory is predicted by solving the following equations (ANSYS 2016):

$\frac{\mathrm{d} \vec{u}_{\mathrm{p}}}{\mathrm{d} t}=F_{\mathrm{D}}\left(\vec{u}-\vec{u}_{\mathrm{p}}\right)+\frac{\vec{g}\left(\rho_{\mathrm{p}}-\rho\right)}{\rho_{\mathrm{p}}}+\vec{F}$

$F_{\mathrm{D}}=\frac{18 \mu}{\rho_{\mathrm{p}} d_{\mathrm{p}}^{2}} \frac{C_{\mathrm{D}} R e}{24}$

$R e \equiv \frac{\rho d_{\mathrm{p}}\left|\vec{u}_{\mathrm{p}}-\vec{u}\right|}{\mu}$

In DPM, the particles with initial size $10 \mu \mathrm{m}$ are released from manikin mouth. The normal respiratory rate for healthy adults is between 12 and 20 breaths per minute, in other words, a respiratory period is about $4 \mathrm{~s}$. The time step is $0.01 \mathrm{~s}$ for the first $0.1 \mathrm{~s}$, and $0.1 \mathrm{~s}$ for the other periods (Ji et al. 2018). Only gravity, buoyancy and drag force are considered, while other forces are neglected (Wei and $\mathrm{Li}$ 2015), the evaporating process of droplets is considered and droplets will be trapped when they contact the wall or fall onto the ground. Chen and Zhao (2010) used an approximation of the exhaled airflow speed in different respiratory activities: normal breath $1 \mathrm{~m} / \mathrm{s}$, speaking $5 \mathrm{~m} / \mathrm{s}$, and cough $10 \mathrm{~m} / \mathrm{s}$, which are also used in this study. In the standard case, human respiration is simplified as a continuous exhalation process without inhalation for a steady simulation, and the initial exhalation velocity is $1 \mathrm{~m} / \mathrm{s}$, basically consistent with the data in the literature. The manikin mouth's hydraulic diameter is $0.02 \mathrm{~m}$ (Liu et al. 2017b), the exhalation temperature is $306 \mathrm{~K}$, and the manikin heat source intensity is $40 \mathrm{~W} / \mathrm{m}^{2}$ (Ji et al. 2018). The temperature of the jet from the pillar inlet is $298 \mathrm{~K}$.

\subsection{Experiment and validation}

To validate the accuracy of the numerical set-up, an additional case is provided to make a comparison with the experimental data. The experiment is conducted in an environmental chamber located in Southeast University. The air pillars composed of cross-flow fans and filter cotton, and the layout is the same as Figure 1, but with differences in scale and pollution source. The jet velocity from air pillar is set as $2.5 \mathrm{~m} / \mathrm{s}$ and burning incense acts as an indoor pollution source. Layout details are shown in Figure 2(a). The particle size distribution between the source and air curtain is measured by using a TSI APS-3321 aerodynamic particle size spectrometer, which can measure particle from 0.5 to $20 \mu \mathrm{m}$ aerodynamic size. Its resolutions are $0.02 \mu \mathrm{m}$ at $1.0 \mu \mathrm{m}$ diameter and $0.03 \mu \mathrm{m}$ at $10 \mu \mathrm{m}$ diameter. The concentration accuracy is $\pm 10 \%$ of reading plus variation from counting statistics. Sampling time can be programmable from 1 second to 18 hours and the average value is output. From the source to the air curtain, a total of 8 points are selected from $0.05 \mathrm{~m}$ to $0.4 \mathrm{~m}$ in the horizontal direction, each data point is measured for $10 \mathrm{~s}$, and the average value of three experiments is recorded. The validation case uses the same parameters as in the experiment. The mole fraction of $\mathrm{N}_{2} \mathrm{O}$ in simulation and the particle counting concentration of $d<0.523 \mu \mathrm{m}, d=1 \mu \mathrm{m}$ and $d=2.5 \mu \mathrm{m}$ in the experiment are compared. Figure 2(b) shows the comparison of concentration in experimental and numerical results. It can be seen that simulation results correspond well with the experimental measurement. The $C / C_{0}$ ratio in the experiment is slightly larger than that in the simulation, probably because

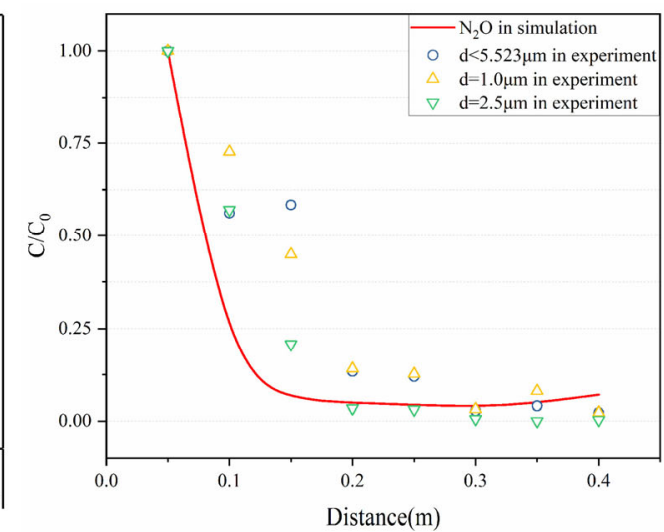

(b)

Fig. 2 Comparison of contaminant concentration between simulation and experiment 
the filtering effect of the return air is not good enough in the experiments to make the air thoroughly purified inside the air pillar. Moreover, contaminants in the experiments contain different gases and particles, which are more complicated than the single trace gas in numerical cases. The results are reasonable and numerical set-up can be validated is reliable.

Nielsen et al. (2003) carried out benchmark tests for Computer Simulated Person. The set-up of the displacement ventilation case is shown in Figure 3(a). The CSP is standing and facing the supply flow. Data such as air velocity in the room are measured. The same simulation is implemented to validate the CSP used in this study. Two vertical in front of manikin are compared with the experimental results. As demonstrated in Figure 3(b), despite a few deficiencies, the air velocities in simulation generally agree well with the experimental data, which shows that the CSP is reliable.

\subsection{Grid independence test}

In the simulation of room air distribution by CFD, all cases related to air curtain are separated into four scenarios and listed in Table 1. Taking Case 1 as an example, three different meshes with the amount of 3,580,688, 4,794,242 and 6,154,407 are generated to find out the least required amount of meshes. Mesh details are shown in Figure 4. Grids are particularly refined around the manikin, where $y^{+}<5$. The minimum orthogonal quality is greater than 0.2 , corresponding to the requirements of calculation. Figure 5 shows the velocity in the exhalation direction at $1.55 \mathrm{~m}$, the height of manikin mouth, by using the three meshes. Results in Mesh 2 and Mesh 3 are almost overlapped with each other. The average relative error of numerical simulation results is $7.5 \%$. Thus, the grid independence of meshes has been verified, and Mesh 2 is used in the following simulations.

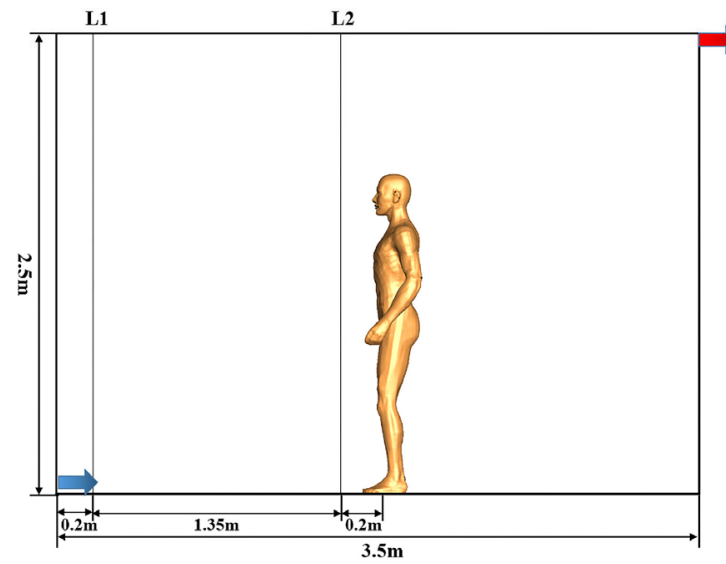

(a)

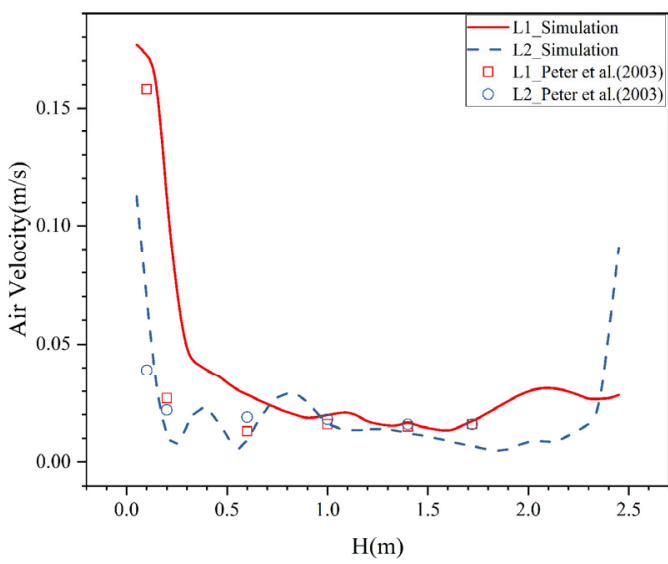

(b)

Fig. 3 Velocity distribution at the two vertical lines (dot: measured data; line: simulation results)

Table 1 Simulation cases for various parameters

\begin{tabular}{|c|c|c|c|c|c|}
\hline Scenario & Case & Enclosure shape & Human-curtain distance (m) & Jet velocity from air pillars $(\mathrm{m} / \mathrm{s})$ & Exhalation mode (velocity $(\mathrm{m} / \mathrm{s})$ ) \\
\hline \multirow{3}{*}{1} & 1 & Quadrilateral & 1.5 & 3.5 & Breath (1.0) \\
\hline & 2 & Quadrilateral & 1.0 & 3.5 & Breath (1.0) \\
\hline & 3 & Quadrilateral & 0.5 & 3.5 & Breath (1.0) \\
\hline \multirow{3}{*}{2} & 1 & Quadrilateral & 1.5 & 3.5 & Breath (1.0) \\
\hline & 4 & Triangle & 1.5 & 3.5 & Breath (1.0) \\
\hline & 5 & Pentagon & 1.5 & 3.5 & Breath (1.0) \\
\hline \multirow{3}{*}{3} & 1 & Quadrilateral & 1.5 & 3.5 & Breath (1.0) \\
\hline & 6 & Quadrilateral & 1.5 & 2.0 & Breath (1.0) \\
\hline & 7 & Quadrilateral & 1.5 & 5.0 & Breath (1.0) \\
\hline \multirow{3}{*}{4} & 1 & Quadrilateral & 1.5 & 3.5 & Breath (1.0) \\
\hline & 8 & Quadrilateral & 1.5 & 3.5 & Speak (5.0) \\
\hline & 9 & Quadrilateral & 1.5 & 3.5 & Cough (10.0) \\
\hline
\end{tabular}




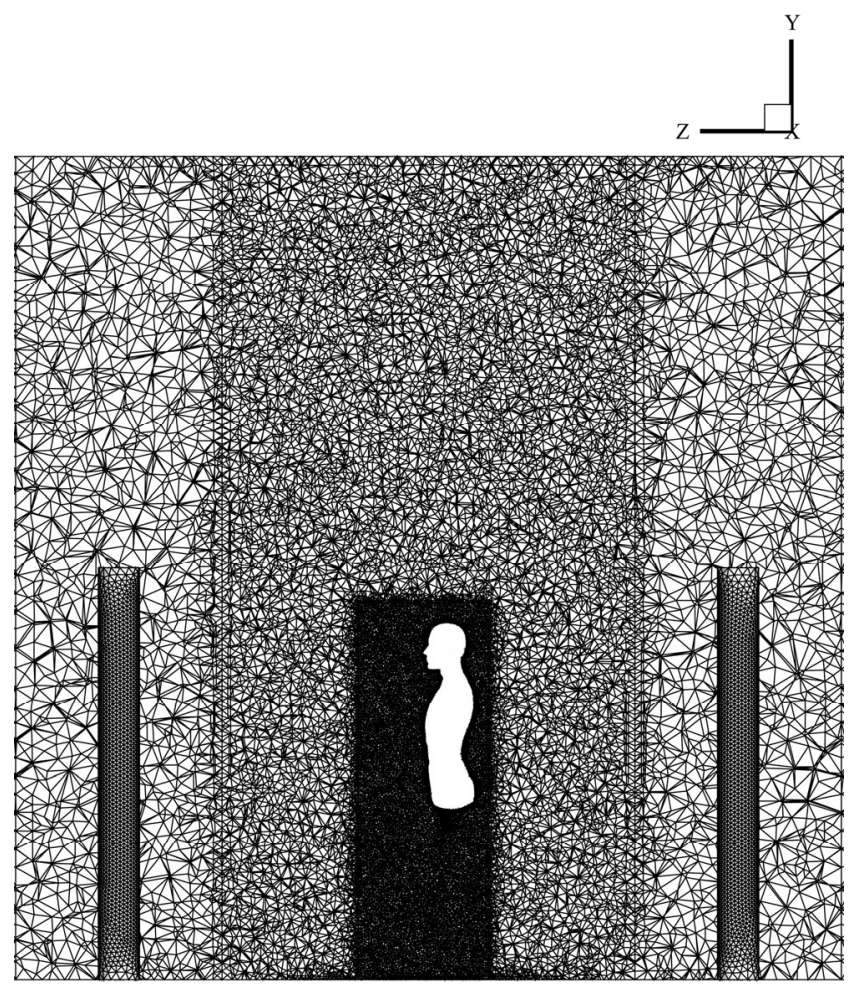

Fig. 4 Mesh detail corresponding to 4,794,242 grid elements

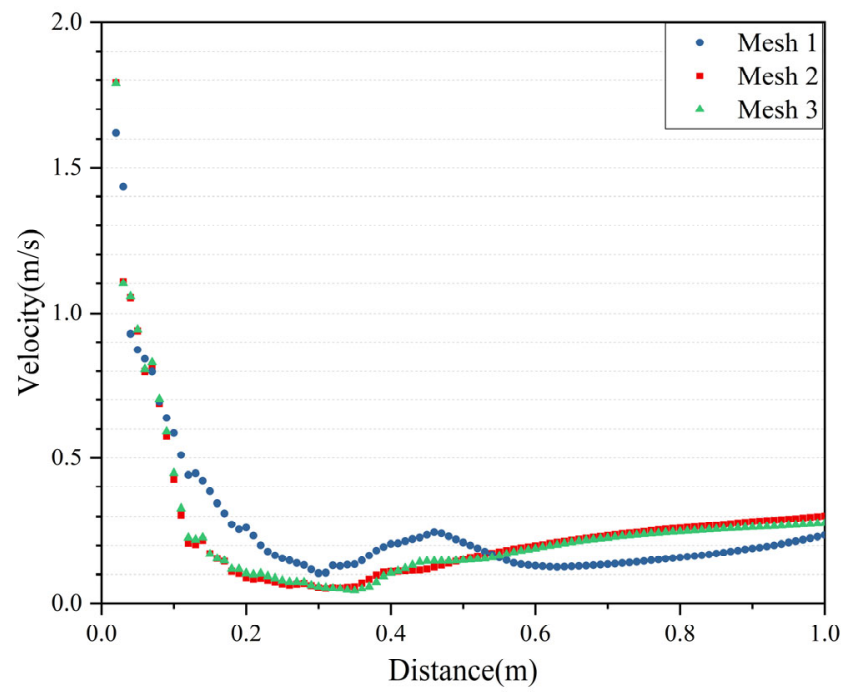

Fig. 5 Comparison of three meshes in calculating velocity of exhalation direction

\section{Results}

Scenarios in Table 1 represent the parameters of air curtain performance, i.e., human-curtain distance $(0.5,1.0,1.5 \mathrm{~m})$, enclosure shape (triangle, quadrilateral, pentagon), jet velocity from air pillar $(2.0,3.5,5.0 \mathrm{~m} / \mathrm{s})$, and exhalation mode (breath, speak, cough), respectively. Each case is denoted as Case \# [enclosure shape; human-curtain distance; jet velocity from air pillar; exhalation mode]. For example, Case 1 is referred to as [quadrilateral; $1.5 \mathrm{~m} ; 3.5 \mathrm{~m} / \mathrm{s}$; breath]. Airflow patterns and dispersion of exhaled contaminants are investigated to explore better design parameters of the air curtain.

\subsection{The airflow patterns with air curtains}

Figure 6 shows the velocity vectors at the height of manikin mouth $(y=1.55 \mathrm{~m})$ under various parameters. A vortexlike clockwise rotation is generated by air pillars and the multidirectional blockage is formed in all cases. The velocity gradually decreases from the inlet to the exhaust. The confinement of air curtains gets more obvious with the shortened human-curtain distance from $1.5 \mathrm{~m}$ to $0.5 \mathrm{~m}$ shown in Figures 6(a), (b) and (c). The exhaled airflow has an impact on the air curtain in front of the manikin, which is more obvious in Figure 6(d). Stronger turbulence is observed along with air curtain with fewer air pillars. As the jet velocity increased from $2 \mathrm{~m} / \mathrm{s}$ to $5 \mathrm{~m} / \mathrm{s}$, illustrated in Figures 6(a), (f) and (g), the entrainment of air curtains also gets stronger, which helps strengthen the isolation performance of air curtains. The exhalation mode only has a slight impact on the velocity distribution between air pillars shown in Figures 6(a), (h) and (i). But airflow tends to cross the curtain with high exhalation velocity, which needs further analysis as a function to the dispersion of exhaled contaminants.

\subsection{The dispersion of exhaled contaminants}

The dispersion of exhaled contaminants is closely related to the airflow patterns generated by air curtains and manikin exhalation modes. Figure 7 and Figure 8 illustrate the top view and side view of $\mathrm{N}_{2} \mathrm{O}$ mole fraction contours under various human-curtain distance, enclosure shape, jet velocity from air pillar, and exhalation mode. Results show airflow is rotated clockwise by the action of air curtain and all air curtains can effectively prevent the contaminants from spreading outwards.

Figure $7(\mathrm{a}, \mathrm{b}, \mathrm{c})$ and Figure $8(\mathrm{a}, \mathrm{b}, \mathrm{c})$ display dispersion of gas tracer under different human-curtain distance varying from $1.5 \mathrm{~m}, 1.0 \mathrm{~m}, 0.5 \mathrm{~m}$. Results in top view show the rotation phenomenon is more obvious with the human-curtain is $1.5 \mathrm{~m}$, while contaminants are confined near the mouth with the human-curtain is $1.0 \mathrm{~m}$ and $0.5 \mathrm{~m}$. Compared to Figure $8(\mathrm{c}), \mathrm{N}_{2} \mathrm{O}$ tends to flow upward due to the plume generated by thermal manikin in Figure 8(a) and Figure 8(b). As human-curtain distance shortened to $0.5 \mathrm{~m}, \mathrm{~N}_{2} \mathrm{O}$ tends to flow downward, which may be owing to the low-pressure zone generated when air curtains are close to manikin. Figure $7(\mathrm{a}, \mathrm{d}, \mathrm{e})$ and Figure $8(\mathrm{a}, \mathrm{d}, \mathrm{e})$ demonstrate the 


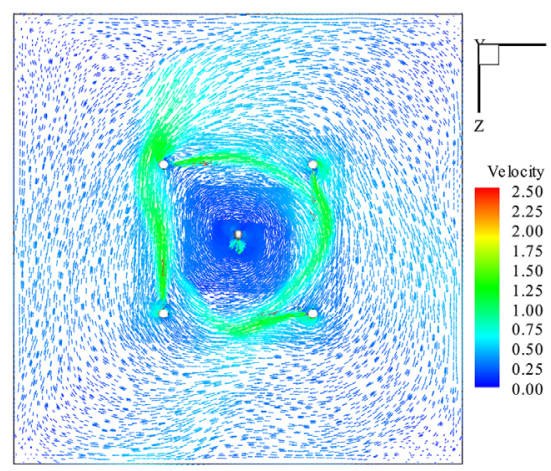

(a)

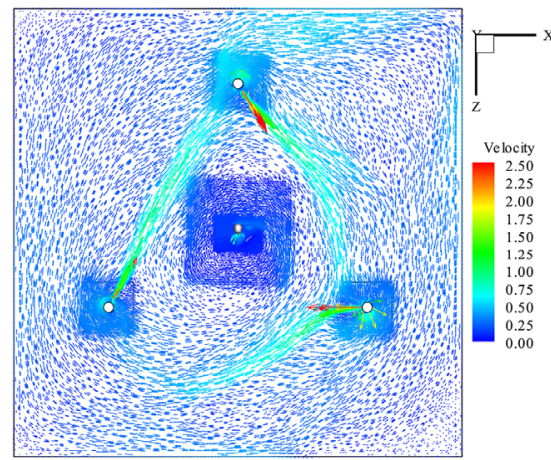

(d)

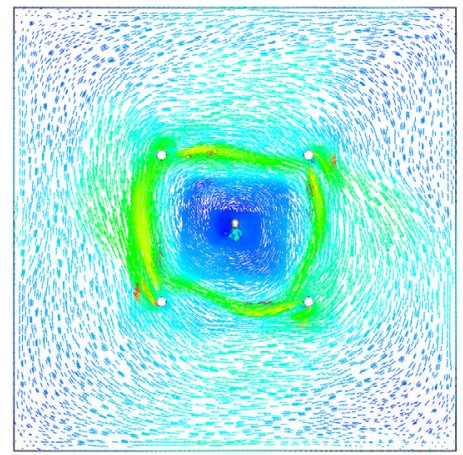

(g)

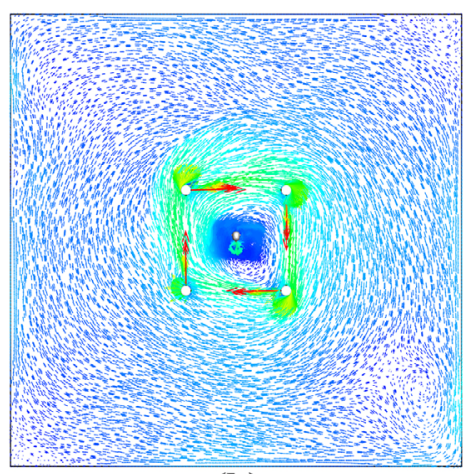

(b)

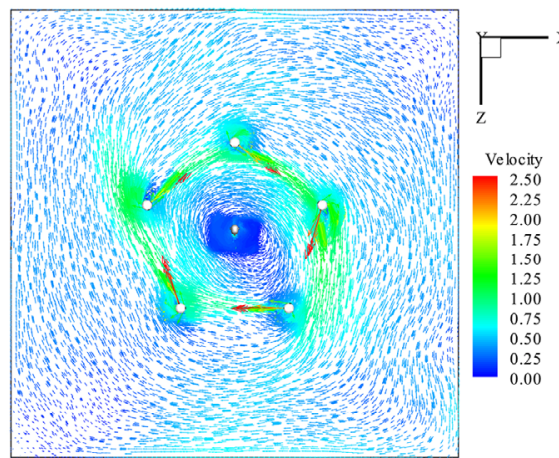

(e)
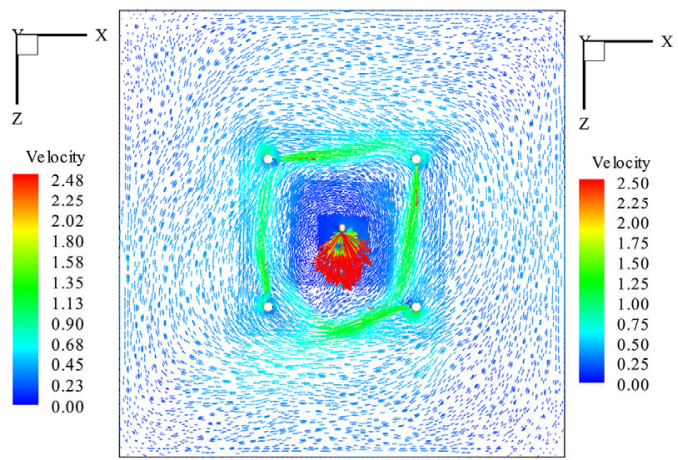

(h)

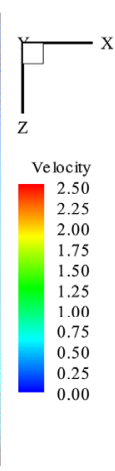

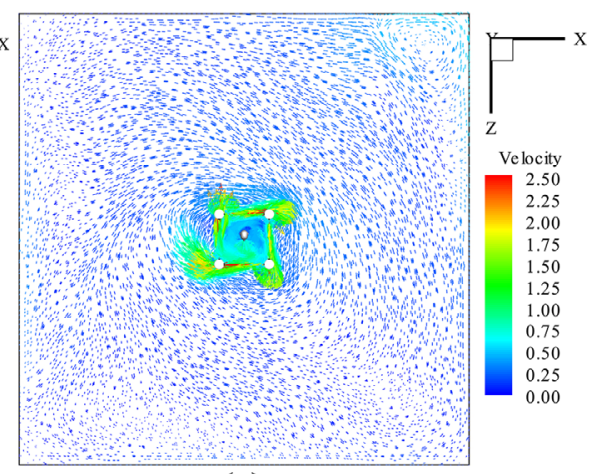

(c)

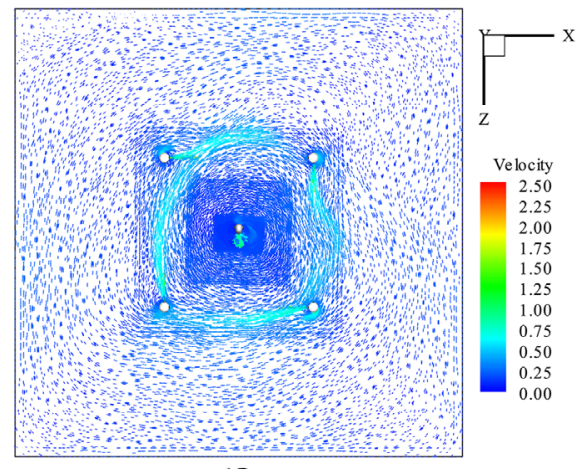

(f)

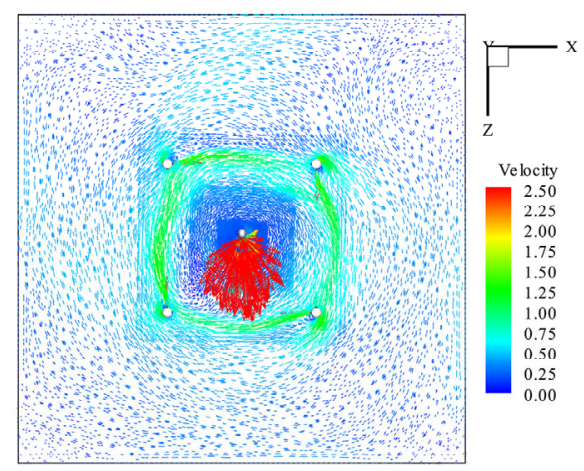

(i)

Fig. 6 Distributions of velocity vectors under various air curtain parameters: (a) Case 1 [quadrilateral;1.5 m; $3.5 \mathrm{~m} / \mathrm{s}$; breath]; (b) Case 2 [quadrilateral; $1.0 \mathrm{~m} ; 3.5 \mathrm{~m} / \mathrm{s}$; breath]; (c) Case 3 [quadrilateral; $0.5 \mathrm{~m} ; 3.5 \mathrm{~m} / \mathrm{s} ;$ breath]; (d) Case 4 [triangle; $1.5 \mathrm{~m} ; 3.5 \mathrm{~m} / \mathrm{s} ;$ breath]; (e) Case 5 [pentagon; $1.5 \mathrm{~m} ; 3.5 \mathrm{~m} / \mathrm{s}$; breath]; (f) Case 6 [quadrilateral; $1.5 \mathrm{~m} ; 2.0 \mathrm{~m} / \mathrm{s}$; breath]; (g) Case 7 [quadrilateral; $1.5 \mathrm{~m} ; 5.0 \mathrm{~m} / \mathrm{s}$; breath]; (h) Case 8 [quadrilateral; $1.5 \mathrm{~m} ; 3.5 \mathrm{~m} / \mathrm{s}$; speak]; (i) Case 9 [quadrilateral; $1.5 \mathrm{~m} ; 3.5 \mathrm{~m} / \mathrm{s}$; cough]

dispersion of gas tracer under different enclosure shapes (quadrilateral, triangle, and pentagon). Compared with quadrilateral and pentagon air curtains, $\mathrm{N}_{2} \mathrm{O}$ can spread over a longer distance inside the triangle air curtain. Besides, the concentration contours are similar with different enclosure shapes. Figure $7(\mathrm{a}, \mathrm{f}, \mathrm{g})$ and Figure $8(\mathrm{a}, \mathrm{f}, \mathrm{g})$ illustrate the dispersion of gas tracer under different jet velocity $(3.5 \mathrm{~m} / \mathrm{s}$, $2 \mathrm{~m} / \mathrm{s}$ and $5 \mathrm{~m} / \mathrm{s}$ ). From the top view, contaminants concentrated on the manikin zone and concentrations are low outside air curtain, which means the air curtain can effectively prevent the contaminants from spreading outwards in the three cases. As jet velocity decreases to $4 \mathrm{~m} / \mathrm{s}$, it is found that $\mathrm{N}_{2} \mathrm{O}$ flows higher and shows further dispersion in Figure 8(f). Figure 7(a, h, i) and Figure 8(a, h, i) display dispersion of gas tracer under different exhalation modes. Compared with breath, $\mathrm{N}_{2} \mathrm{O}$ can disperse farther under speak and cough. Although having higher exhalation velocity, tracer gas rotates when approaching the air curtain and does not break through the confinement of air curtain.

The $\mathrm{N}_{2} \mathrm{O}$ concentration contours revel that humancurtain distance has an obvious effect in the dispersion of exhaled contaminants. As distance shortens to $0.5 \mathrm{~m}, \mathrm{~N}_{2} \mathrm{O}$ shows a tendency to flow downward even if the buoyance of the hot plume exists. Profiles of tracer gas $\mathrm{N}_{2} \mathrm{O}$ are 


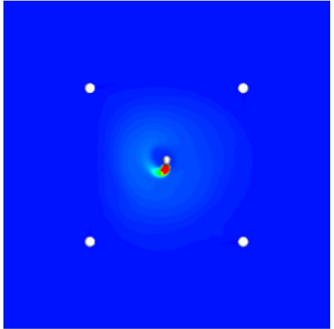

(a)

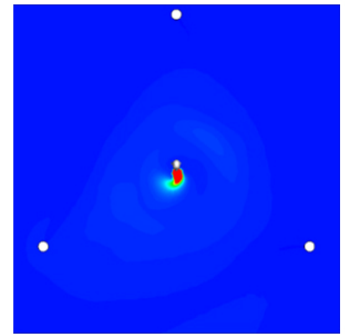

(d)

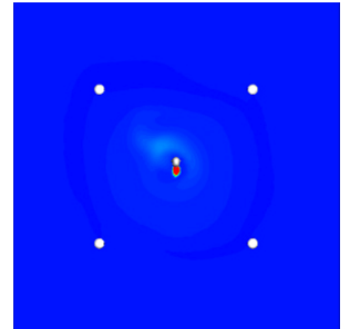

(g)

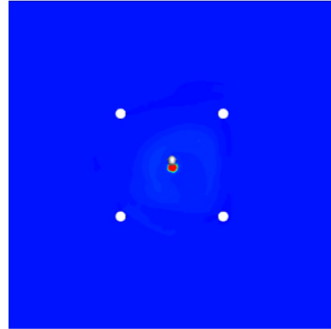

(b)

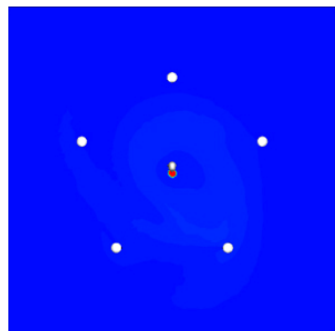

(e)

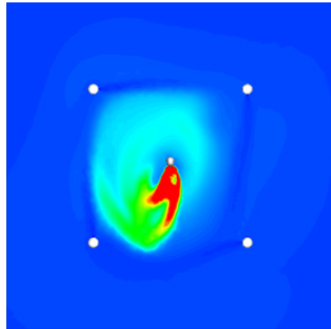

(h)

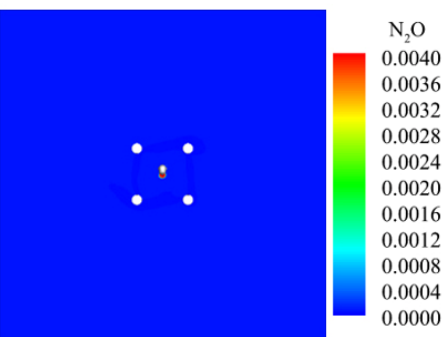

(c)

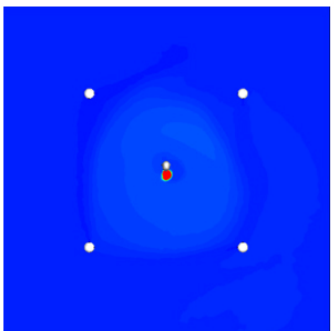

(f)

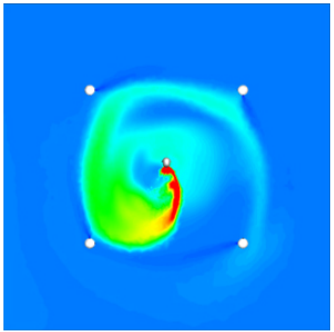

(i)

Fig. 7 The top view of $\mathrm{N}_{2} \mathrm{O}$ mole fraction under various air curtain parameters: (a) Case 1 [quadrilateral;1.5 m; $3.5 \mathrm{~m} / \mathrm{s}$; breath]; (b) Case 2 [quadrilateral; $1.0 \mathrm{~m} ; 3.5 \mathrm{~m} / \mathrm{s}$; breath]; (c) Case 3 [quadrilateral; $0.5 \mathrm{~m} ; 3.5 \mathrm{~m} / \mathrm{s}$; breath]; (d) Case 4 [triangle; $1.5 \mathrm{~m} ; 3.5 \mathrm{~m} / \mathrm{s} ; \mathrm{breath}$ ]; (e) Case 5 [pentagon; $1.5 \mathrm{~m} ; 3.5 \mathrm{~m} / \mathrm{s}$; breath]; (f) Case 6 [quadrilateral; $1.5 \mathrm{~m} ; 2.0 \mathrm{~m} / \mathrm{s}$; breath]; (g) Case 7 [quadrilateral; $1.5 \mathrm{~m} ; 5.0 \mathrm{~m} / \mathrm{s}$; breath]; (h) Case 8 [quadrilateral; $1.5 \mathrm{~m} ; 3.5 \mathrm{~m} / \mathrm{s}$; speak]; (i) Case 9 [quadrilateral; $1.5 \mathrm{~m} ; 3.5 \mathrm{~m} / \mathrm{s}$; cough]

similar with different enclosure shapes and jet velocities, but there are some gaps in value. Exhalation modes have an apparent effect on the dispersion of exhaled contaminants. Intense exhalation activities will increase the difficulty of cutting-off performance.

\subsection{The variation of exhaled contaminants in the horizontal direction}

To quantify the performance of air curtains on the confinement of exhaled contaminants, the concentration variations of tracer gas along with the horizontal distance from the manikin mouth are shown in Figure 9. Mixing ventilation with the same air flux is set as a reference case to be compared with air curtain of different human-curtain distance $(0.5,1.0,1.5 \mathrm{~m})$. Based on these, the impact of enclosure shape (triangle, quadrilateral, pentagon), and jet velocity from air pillar $(2.0,3.5,5.0 \mathrm{~m} / \mathrm{s})$ are investigated here to further assess the performance of different air curtain configurations. The influence of human exhalation mode (breath, speak, cough) is also compared to verify the device applicability.

The horizontal variation of exhaled contaminants from manikin's mouth under air curtains with different humancurtain distances and mixing ventilation are illustrated in Figure 9(a), revealing that the rapid falling of $\mathrm{N}_{2} \mathrm{O}$ mole fraction mainly occurs in the first $0.3 \mathrm{~m}$ and the location moves far as the human-curtain distance increases. The positive value of the abscissa represents the exhalation direction. Compared with mixing ventilation, the concentration of tracer gas with air curtain is relatively not uniform around the manikin, but the concentration is lower and keeps low values (less $1 \times 10^{-4}$ ) outside the air curtain. The higher concentration inside air curtain and lower concentration outside air curtain mean the air curtain can confine contaminants inside the air curtain and effectively prevent them from spreading outwards. The average concentrations outside the air curtain are used for comparison with the same range of data in mixing ventilation. Results show that the average mole fractions of exhaled contaminants decrease $4.3 \%$ for human-distance $1.5 \mathrm{~m}, 18.2 \%$ for human-distance $1.0 \mathrm{~m}, 19.6 \%$ for human- distance $0.5 \mathrm{~m}$. There is a little 


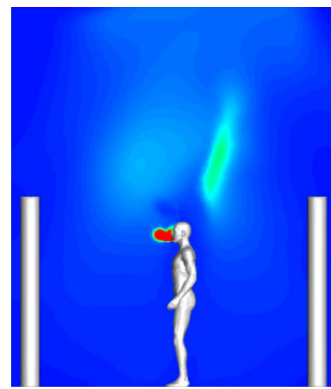

(a)

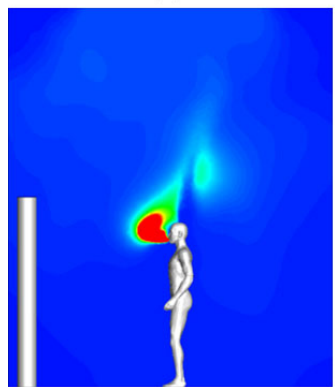

(d)

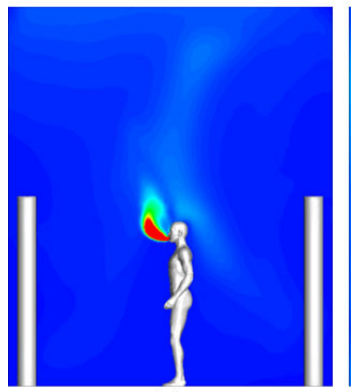

(g)

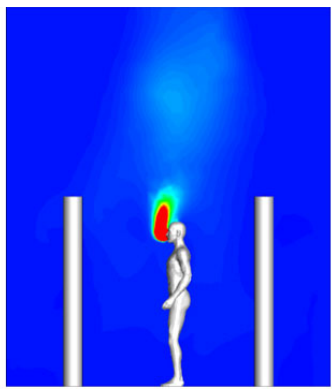

(b)

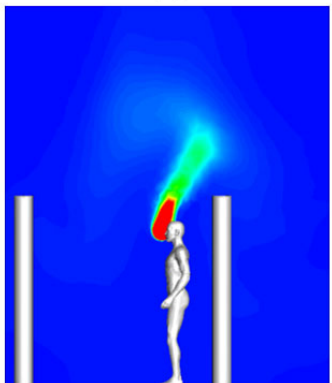

(e)

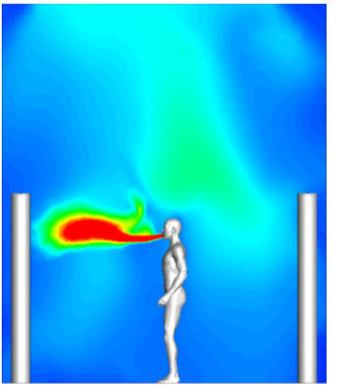

(h)

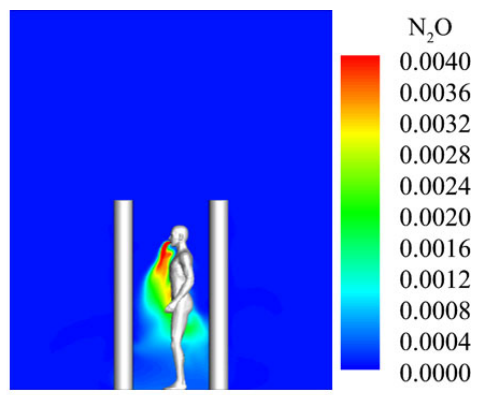

(c)

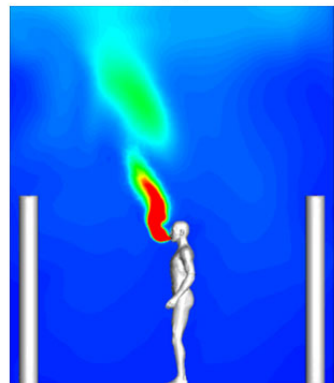

(f)

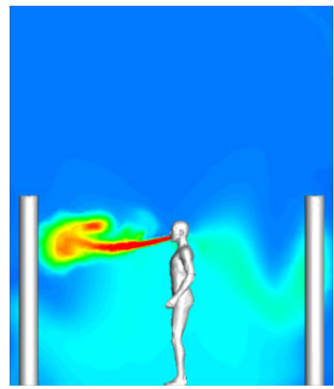

(i)

Fig. 8 The side view of $\mathrm{N}_{2} \mathrm{O}$ mole fraction under various air curtain parameters: (a) Case 1 [quadrilateral;1.5 m; $3.5 \mathrm{~m} / \mathrm{s}$; breath]; (b) Case 2 [quadrilateral; $1.0 \mathrm{~m} ; 3.5 \mathrm{~m} / \mathrm{s}$; breath]; (c) Case 3 [quadrilateral; $0.5 \mathrm{~m} ; 3.5 \mathrm{~m} / \mathrm{s}$; breath]; (d) Case 4 [triangle; $1.5 \mathrm{~m} ; 3.5 \mathrm{~m} / \mathrm{s}$; breath]; (e) Case 5 [pentagon; $1.5 \mathrm{~m} ; 3.5 \mathrm{~m} / \mathrm{s}$; breath]; (f) Case 6 [quadrilateral; $1.5 \mathrm{~m} ; 2.0 \mathrm{~m} / \mathrm{s}$; breath]; (g) Case 7 [quadrilateral; $1.5 \mathrm{~m}$; $5.0 \mathrm{~m} / \mathrm{s}$; breath]; (h) Case 8 [quadrilateral; $1.5 \mathrm{~m} ; 3.5 \mathrm{~m} / \mathrm{s}$; speak]; (i) Case 9 [quadrilateral; $1.5 \mathrm{~m} ; 3.5 \mathrm{~m} / \mathrm{s}$; cough]

increase in the slope of $\mathrm{N}_{2} \mathrm{O}$ dropping due to the action of air curtain when crossing the air curtain.

Figure 9(b) shows the horizontal variation of exhaled contaminants from manikin's mouth under different enclosure shapes, which demonstrates that the $\mathrm{N}_{2} \mathrm{O}$ mole fraction decreases rapidly after exhalation, leading to the maximum concentration is near the manikin. Compared with triangle air curtain, the $\mathrm{N}_{2} \mathrm{O}$ mole fraction declines quickly in the beginning and drops a lower value within $0.2-0.5 \mathrm{~m}$ for quadrilateral and pentagon air curtains. At the position of air curtains, $\mathrm{N}_{2} \mathrm{O}$ mole fractions in three air curtains decrease to a low level, less $2 \times 10^{-4}$. The average mole fractions of exhaled contaminants outside air curtain are about 0.000088 for triangle air curtain, 0.000062 for quadrilateral air curtain, and 0.000037 for pentagon air curtain. The sequence of blocking effects of the air curtains is pentagon $>$ quadrilateral $>$ triangle in the studied cases. There is a little increase in the slope of $\mathrm{N}_{2} \mathrm{O}$ dropping near the air curtain. To some extent, increasing the number of air pillars can reduce the dispersion of exhaled contaminants.

Figure 9(c) reveals the horizontal variation of exhaled contaminants from manikin's mouth under different jet velocity. The $\mathrm{N}_{2} \mathrm{O}$ mole fractions have the same trend and attenuate quickly within $0.3 \mathrm{~m}$, subsequently change slowly as the distance increases. And the mole fraction of $\mathrm{N}_{2} \mathrm{O}$ is about $2 \times 10^{-4}$ near air curtains when the jet velocity is $2.0 \mathrm{~m} / \mathrm{s}$, correspondingly, this value is less than $1 \times 10^{-4}$ near air curtains when the jet velocities are $3.5 \mathrm{~m} / \mathrm{s}$ and $5.0 \mathrm{~m} / \mathrm{s}$. The average mole fractions of exhaled contaminants outside air curtain are about 0.000115 for jet velocity $2.0 \mathrm{~m} / \mathrm{s}, 0.000062$ for jet velocity $3.5 \mathrm{~m} / \mathrm{s}$, and 0.000048 for jet velocity $5.0 \mathrm{~m} / \mathrm{s}$. As the jet velocity decreases to $2.0 \mathrm{~m} / \mathrm{s}$, the exhalation airflow disperses farther, and the blocking effect is worse than other cases, while the gap between $3.5 \mathrm{~m} / \mathrm{s}$ and $5.0 \mathrm{~m} / \mathrm{s}$ is not obvious. Besides, there is an apparent increase in the slope of $\mathrm{N}_{2} \mathrm{O}$ dropping near the air curtain. These results indicate 


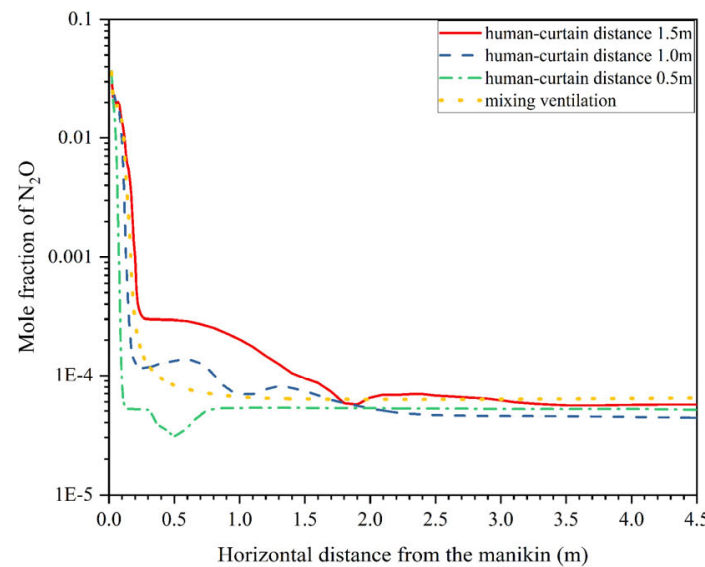

(a)

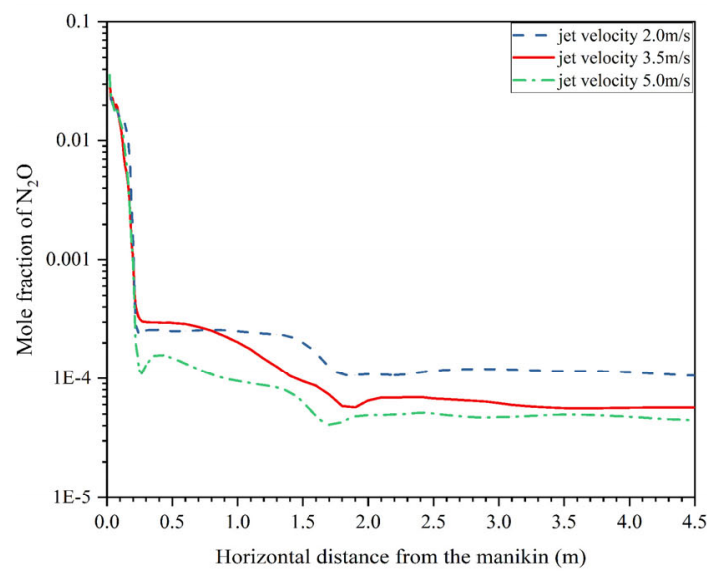

(c)

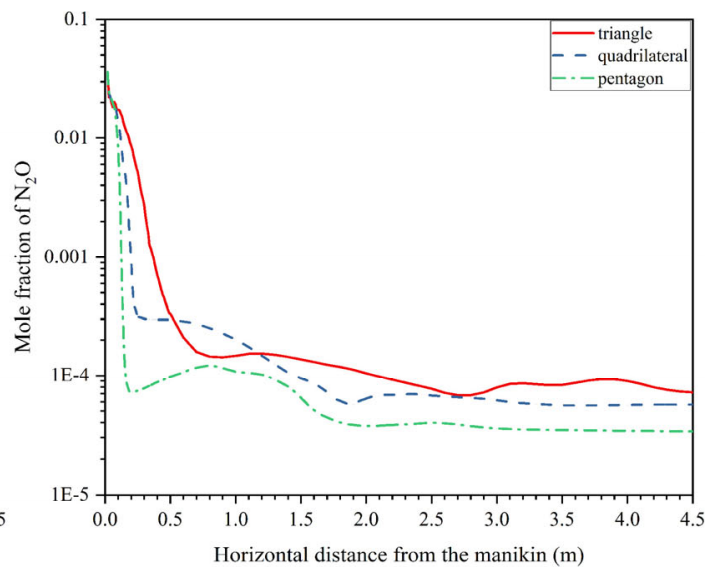

(b)

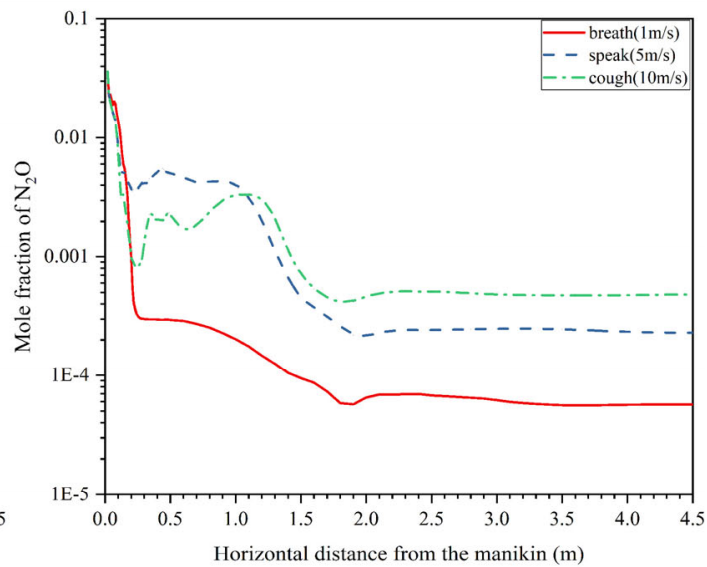

(d)

Fig. 9 The mole fraction of $\mathrm{N}_{2} \mathrm{O}$ along with horizontal distance from the manikin's mouth: (a) human-curtain distance [quadrilateral; $1.5 \mathrm{~m}-1.0 \mathrm{~m}-0.5 \mathrm{~m} ; 3.5 \mathrm{~m} / \mathrm{s} ; 1 \mathrm{~m} / \mathrm{s}$ ]; (b) enclosure shape [triangle-quadrilateral-pentagon; $1.5 \mathrm{~m} ; 3.5 \mathrm{~m} / \mathrm{s} ; 1 \mathrm{~m} / \mathrm{s}$ ]; (c) jet velocity from air pillar [quadrilateral; $1.5 \mathrm{~m} ; 2.0 \mathrm{~m} / \mathrm{s}-3.5 \mathrm{~m} / \mathrm{s}-5.0 \mathrm{~m} / \mathrm{s} ; 1 \mathrm{~m} / \mathrm{s}$ ]; (d) exhalation mode [quadrilateral;1.5 m; $3.5 \mathrm{~m} / \mathrm{s} ;$ breath-speak-cough]

that increasing jet velocity can improve the blockage effect, but the performance improvement of air curtains is not faster than velocity increase.

Figure 9(d) displays the horizontal variation of exhaled contaminants from manikin's mouth under different exhalation modes. The $\mathrm{N}_{2} \mathrm{O}$ mole fractions show apparent fluctuations from $0.2 \mathrm{~m}$ to $1.0 \mathrm{~m}$ for speak and cough, different with the $\mathrm{N}_{2} \mathrm{O}$ mole fraction for breath. This phenomenon may be induced by the interaction between the strong momentum of the exhaled jet and the airflow pattern formed by the air curtain. Additionally, the mole fraction of $\mathrm{N}_{2} \mathrm{O}$ is less $1 \times 10^{-4}$ near the air curtain for breath, while the mole fraction of $\mathrm{N}_{2} \mathrm{O}$ is significantly higher, approximately 0.001 , for speak and cough. The average mole fractions of exhaled contaminants outside air curtain are about 0.000247 for speak and 0.000479 for cough, which means it may be more difficult to control the contaminant in the intense exhalation activity. But for the cases of speak and cough, the $\mathrm{N}_{2} \mathrm{O}$ concentration outside the air curtain is also significantly lower than that inside the curtain. This indicates that the air curtains can make some confinement on the dispersion of exhaled contaminants whatever exhalation modes are.

\section{Discussion}

The $\mathrm{N}_{2} \mathrm{O}$ mole fraction rises again after crossing the air curtain in all cases, which may be because that the jet from air pillar has engulfed a lot of ambient air and widened the influence area in the process of flowing forward. This can be used as an explanation for that the obvious decrease of tracer gas near the air curtain can last for some distance after crossing the air curtain. Exhaled airflow tends to flow upside due to the thermal plume. However, exhaled airflow overcomes the plume generated by thermal manikin and tends to flow downward as the human-curtain distance shortens to $0.5 \mathrm{~m}$, which may be owing to the low-pressure zone generated when air curtains are close to human. The threshold distance where the exhaled airflow flows downward may be very important to change the dispersion direction 
of exhaled contaminants and deserves further study. Concentration contours and blocking effects under different air curtain shape indicate that the air curtain may have better blockage effect as the number of air pillars increase because the blockage direction is more comprehensive this moment. It can be guessed it has better performance when the enclosure shape is close to a circle. The decreasing tendency of tracer gas between jet velocity $3.5 \mathrm{~m} / \mathrm{s}$ and $5.0 \mathrm{~m} / \mathrm{s}$ is similar. Notably, the average mole fraction of $\mathrm{N}_{2} \mathrm{O}$ outside air curtain increases about $86 \%$, i.e. from 0.000062 to 0.000115 as jet velocity decreases from $3.5 \mathrm{~m} / \mathrm{s}$ to $2.0 \mathrm{~m} / \mathrm{s}$, while the value decreases about $23 \%$, i.e. from 0.000062 to 0.000048 as jet velocity increases from $3.5 \mathrm{~m} / \mathrm{s}$ to $5.0 \mathrm{~m} / \mathrm{s}$. It may be because that air curtains with high jet velocity will easily entrain exhaled airflow and weaken its confinement performance. So increasing jet velocity can slightly improve the performance of air curtain, but the effect is not very obvious when the velocity increases to a certain extent.

Coughing is simulated as steady model in this work, but steady simulation may not reflect the real exhalation airflow in transient respiratory activities. Habchi et al. (2015) compared the steady and transient modeling of IPE and found that steady modeling over-predicted the inhaled dose of particle. Therefore, a transient model of pulse exhalation is carried out to simulate the exhaled airflow propagation of coughing process. The duration time of cough behavior is set as $0.1 \mathrm{~s}$ (Chen and Zhao 2010). Moreover, an animation of exhaled droplets $(10 \mu \mathrm{m})$ for transient coughing simulation is available in the Electronic Supplementary Material (ESM) in the online version of this paper. The dispersion of tracer gas and the droplet trajectories from the droplet birth at $0 \mathrm{~s}$ to $8 \mathrm{~s}$ (about two respiratory periods) are investigated for transient cough.

Figure 10 shows the $\mathrm{N}_{2} \mathrm{O}$ mole fraction in transient coughing simulation. As time increases, the concentration of $\mathrm{N}_{2} \mathrm{O}$ gradually decreases and the contaminant does not cross the curtain in a coughing process. Animation 1 (in the ESM of the online version of this paper) presents the droplet trajectory from the droplet birth at $0 \mathrm{~s}$ to $8 \mathrm{~s}$, it can be seen that droplets rotate clockwise owing to the airflow caused by the air curtain. Droplets do not flow forward in the horizontal direction and are mainly concentrated within 1 $\mathrm{m}$, which means the airflow formed by the air curtains can block the droplet from spreading out directly. The steady coughing simulation overestimates the concentration of exhaled contaminants compared with transient coughing simulation. The results in steady simulation can reflect the maximal risk induced by coughing to some extent, but coughing in transient is more suitable for the actual needs of the evaluation of infection risk.

\section{Conclusions}

This study carried out a numerical simulation to investigate the performance of air curtain on the confinement of exhaled contaminants. Air curtain has great potential in reducing the cross-infection risk, which owing to the cutting off phenomena and a vortex-like clockwise rotation of exhaled flow generated by air pillars. The exhaled contaminants are concentrated around the source and can drop to a low value outside the air curtains in all cases.

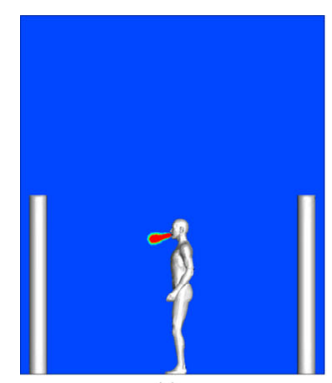

(a)

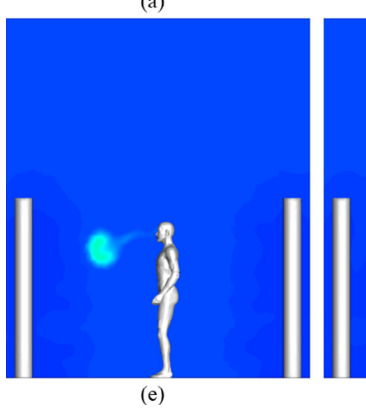

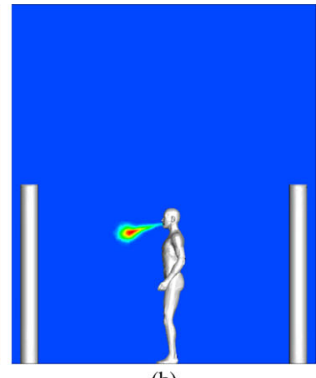

(b)

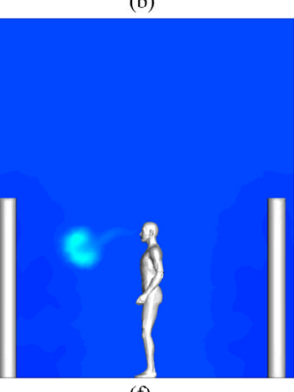

(f)

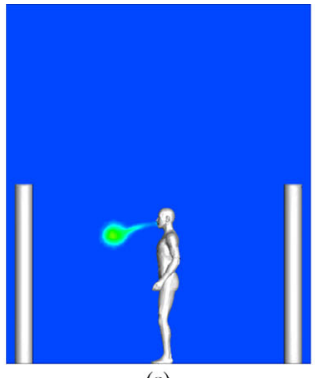

(c)

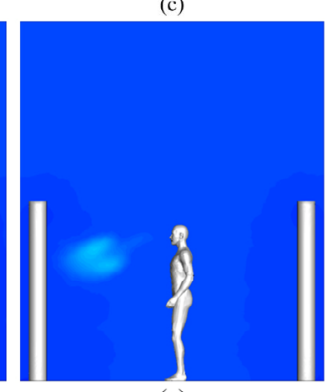

(g)

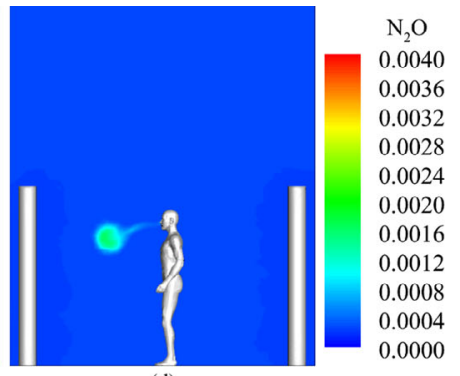

(d)

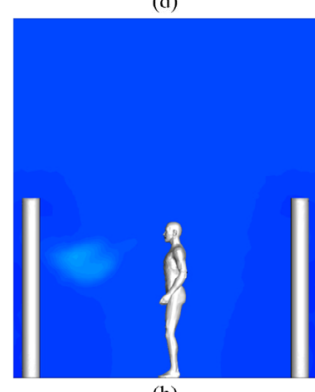

(h)

Fig. 10 The $\mathrm{N}_{2} \mathrm{O}$ mole fraction in transient coughing simulation: (a) time $=0.1 \mathrm{~s}$; (b) time $=0.5 \mathrm{~s}$; (c) time $=1 \mathrm{~s}$; (d) time = $2 \mathrm{~s}$; (e) time = $3 \mathrm{~s}$; (f) time $=4 \mathrm{~s}$; (g) time $=6 \mathrm{~s}$; (h) time $=8 \mathrm{~s}$ 
Compared with mixing ventilation of same flux, results in air curtains of different human-curtain distance reveal that the average mole fraction of exhaled contaminants outside air curtain decreases $4.3 \%-19.6 \%$. Shortening the humancurtain distance can improve the performance of air curtain and may change the direction of exhaled airflow. Moreover, increasing the number of air pillars can reduce the dispersion of exhaled contaminants, and the sequence of effects is pentagon $>$ quadrilateral $>$ triangle in the studied cases. It may have better performance when the enclosure shape is close to a circle. Besides, higher jet velocity is better for improving the confinement performance, but it is not necessary to increase the velocity all the time. For exhalation modes, it is more challenging to control exhaled contaminants when the exhalation velocity is high (such as cough) in steady model, but results in transient simulation show air curtain can block the penetration of the exhaled contaminant effectively. Overall, air curtains could effectively prevent the dispersion of contaminants exhaled by a manikin. The air curtain device in this work can be easily used in hospital wards and other places. It deserves further research and development.

Nevertheless, there are some limitations to this work. For instance, the cross-infection risk should also depend on other considerations, such as the existence of the susceptible and their activity level, which are ignored in this study. Besides, covering the mouth when coughing is more in line with the actual situation and more meaningful, which deserves further study.

\section{Acknowledgements}

The work was supported by the National Natural Science Foundation of China (No. 51778128), the National Key Research and Development Program of China (2018YFC1200100) and the Entrepreneurship Leadership Project in Guangzhou Development Zone of China (CY2018-003).

Electronic Supplementary Material (ESM): supplementary material is available in the online version of this article at https://doi.org/10.1007/s12273-020-0667-5. The ESM file presents the animation of the droplet trajectory from the droplet birth at $0 \mathrm{~s}$ to $8 \mathrm{~s}$

\section{References}

ANSYS (2016). ANSYS Fluent. Theory Guide Release 17.0. Canonsburg, PA, USA: ANSYS Inc.

Cao G, Heikkinen J, Järnström H (2011a). Protection of office workers from exposure to respiratory diseases by a novel ventilation system. In: Proceedings of the Indoor Air 2011, Austin, USA.
Cao Z, Han H, Gu B (2011b). A novel optimization strategy for the design of air curtains for open vertical refrigerated display cases. Applied Thermal Engineering, 31: 3098-3105.

Cao G, Sirén K, Kilpeläinen S (2014). Modelling and experimental study of performance of the protected occupied zone ventilation. Energy and Buildings, 68: 515-531.

Chao CYH, Wan MP, Morawska L, Johnson GR, Ristovski ZD, et al. (2009). Characterization of expiration air jets and droplet size distributions immediately at the mouth opening. Journal of Aerosol Science, 40: 122-133.

Chen C, Zhao B (2010). Some questions on dispersion of human exhaled droplets in ventilation room: answers from numerical investigation. Indoor Air, 20: 95-111.

Ching WH, Leung MKH, Leung DYC, Li Y, Yuen PL (2008). Reducing risk of airborne transmitted infection in hospitals by use of hospital curtains. Indoor and Built Environment, 17: 252-259.

Ciocănea A, Dragomirescu A (2013). Modular ventilation with twin air curtains for reducing dispersed pollution. Tunnelling and Underground Space Technology, 37: 180-198.

Cowling BJ, Zhou Y, Ip DKM, Leung GM, Aiello AE (2010). Face masks to prevent transmission of influenza virus: a systematic review. Epidemiology and Infection, 138: 449-456.

Fairchild CI, Stampfer JF (1987). Particle concentration in exhaled breath. American Industrial Hygiene Association Journal, 48: 948-949.

Ferkol T, Schraufnagel D (2014). The global burden of respiratory disease. Annals of the American Thoracic Society, 11: 404-406.

Gao N, Niu J, Morawska L (2008). Distribution of respiratory droplets in enclosed environments under different air distribution methods. Building Simulation, 1: 326-335.

Gil-Lopez T, Castejon-Navas J, Galvez-Huerta MA, O’Donohoe PG (2014). Energetic, environmental and economic analysis of climatic separation by means of air curtains in cold storage rooms. Energy and Buildings, 74: 8-16.

Goubran S, Qi D, Wang LL (2017). Assessing dynamic efficiency of air curtain in reducing whole building annual energy usage. Building Simulation, 10: 497-507.

Habchi C, Ghali K, Ghaddar N (2015). Transient transport model of particles resulting from high momentum respiratory activities: Inter-personal exposure. Building and Environment, 94: 54-67.

Ji Y, Qian H, Ye J, Zheng X (2018). The impact of ambient humidity on the evaporation and dispersion of exhaled breathing droplets: A numerical investigation. Journal of Aerosol Science, 115: 164-172.

King MF, Noakes CJ, Sleigh PA, Camargo-Valero MA (2013). Bioaerosol deposition in single and two-bed hospital rooms: a numerical and experimental study. Building and Environment, 59: 436-447.

Kwon SB, Park J, Jang J, Cho Y, Park DS, et al. (2012). Study on the initial velocity distribution of exhaled air from coughing and speaking. Chemosphere, 87: 1260-1264.

Li Y, Yu ITS, Xu P, Lee JHW, Wong TW, et al. (2004). Predicting super spreading events during the 2003 severe acute respiratory syndrome epidemics in Hong Kong and Singapore. American Journal of Epidemiology, 160: 719-728.

Li Y, Huang X, Yu ITS, Wong TW, Qian H (2005). Role of air distribution in SARS transmission during the largest nosocomial outbreak in Hong Kong. Indoor Air, 15: 83-95. 
Lindsley WG, Pearce TA, Hudnall JB, Davis KA, Davis SM, et al. (2012). Quantity and size distribution of cough-generated aerosol particles produced by influenza patients during and after illness. Journal of Occupational and Environmental Hygiene, 9: 443-449.

Liu L, Li Y, Nielsen PV, Wei J, Jensen RL (2017a). Short-range airborne transmission of expiratory droplets between two people. Indoor Air, 27: 452-462.

Liu L, Wei J, Li Y, Ooi A (2017b). Evaporation and dispersion of respiratory droplets from coughing. Indoor Air, 27: 179-190.

Liu F, Zhang C, Qian H, Zheng X, Nielsen PV (2019a). Direct or indirect exposure of exhaled contaminants in stratified environments using an integral model of an expiratory jet. Indoor Air, 29: 591-603.

Liu J, Dalgo DA, Zhu S, Li H, Zhang L, Srebric J (2019b). Performance analysis of a ductless personalized ventilation combined with radiant floor cooling system and displacement ventilation. Building Simulation, 12: 905-919.

Luo N, Li A, Leng B, Xu L, Liu X (2017). Smoke confinement with multi-stream air curtain at stairwell entrance. Procedia Engineering, 205: 337-344.

Navaz HK, Amin M, Dabiri D, Faramarzi R (2005). Past, present, and future research toward air curtain performance optimization. ASHRAE Transactions, 111(1): 1083-1088.

Nielsen PV, Murakami S, Kato S, Topp C, Yang Y-H (2003). Benchmark tests for a computer simulated person. Aalborg University, Indoor Environmental Engineering.

Nielsen PV (2015). Fifty years of CFD for room air distribution. Building and Environment, 91: 78-90.

Qian H, Li Y (2010). Removal of exhaled particles by ventilation and deposition in a multibed airborne infection isolation room. Indoor Air, 20: 284-297.

Qian H, Zhang CY, Zheng XH (2018). The function of aerosols in transmitting and infecting of respiratory infectious diseases and its risk prediction. Chinese Science Bulletin 63: 931-939. (in Chinese)
Rivera J, Elicer-Cortés JC, Pavageau M (2011). Turbulent heat and mass transfer through air curtains devices for the confinement of heat inside tunnels. International Communications in Heat and Mass Transfer, 38: 688-695.

Sekhar C, Zheng L (2018). Study of an integrated personalized ventilation and local fan-induced active chilled beam air conditioning system in hot and humid climate. Building Simulation, 11: 787-801.

Shih Y-C, Yang A-S, Lu C-W (2011). Using air curtain to control pollutant spreading for emergency management in a cleanroom. Building and Environment, 46: 1104-1114.

Sirén K (2003). Technical dimensioning of a vertically upwards blowing air curtain-part I. Energy and Buildings, 35: 681-695.

Wei J, Li Y (2015). Enhanced spread of expiratory droplets by turbulence in a cough jet. Building and Environment, 93: 86-96.

WHO (2020). Coronavirus disease 2019 (COVID-2019) situation reports. Situation report by April 21, 2020. https://www.who.int/ docs/default-source/coronaviruse/situation-reports/20200421-sit rep-92-covid-19.pdf?sfvrsn=38e6b06d_4. Accessed 21 Apr 2020.

Xie X, Li Y, Sun H, Liu L (2009). Exhaled droplets due to talking and coughing. Journal of the Royal Society Interface, 6(Suppl 6): S703-S714.

Yan Y, Li X, Tu J (2017). Numerical investigations of the effects of manikin simplifications on the thermal flow field in indoor spaces. Building Simulation, 10: 219-227.

Yan Y, Li X, Tu J (2019). Thermal effect of human body on cough droplets evaporation and dispersion in an enclosed space. Building and Environment, 148: 96-106.

Zhao F-Y, Shen G, Liu K-J, Xu Y, Liu D, et al. (2018). Room airborne pollutant separation by the use of air curtains in the large building enclosure: Infiltration efficiency and partial enclosure ventilation rate. Journal of Building Engineering, 18: 386-394.

Zhu S, Kato S, Yang JH (2006). Study on transport characteristics of saliva droplets produced by coughing in a calm indoor environment. Building and Environment, 41: 1691-1702. 